\title{
Metabolic Inequality and Its Impact on Efficient Contraction and Convergence of International Material Resource Use
}

\author{
Juan Antonio Duro ${ }^{\mathrm{a}}$, Anke Schaffartzik ${ }^{\mathrm{b}}$, Fridolin Krausmann ${ }^{\mathrm{b}}$ \\ aEconomics Department, CREIP, Universitat Rovira i Virgili, Avinguda Universitat 1, 43204 \\ Reus, Spain \\ 'Institute of Social Ecology, Alpen-Adria Universitaet, Schottenfeldgasse 29, 1070 Vienna, \\ Austria
}

Accepted final version of:

Duro, J.A., Schaffartzik, A., Krausmann, F., 2018. Metabolic inequality and its impact on efficient contraction and convergence of international material resource use. Ecological Economics 145, 430-440. https://doi.org/10.1016/i.ecolecon.2017.11.029. 


\begin{abstract}
:
Absolute reductions in global resource use are a precondition for sustainability. Yet, many countries must increase their resource use in the process of economic development and industrialization. In this dilemma, efficient contraction and convergence is viewed as a potential solution: Per capita resource use must internationally converge below the currently high level of industrial countries in order to contract global resource use; improved resource efficiency safeguards economic prosperity and growth. We have conducted an analysis of the international inequality in material use and of the role of material intensity and affluence as explanatory variables for a sample of approximately 100 countries between 1960 and 2010 . During the period of explosive growth of global material use by 20 billion tons between 2000 and 2010, international inequality no longer decreased. Efficiency gains do not suffice to offset increasing affluence. We are not on the pathway of 'efficient contraction and convergence'. The developments of the early 21st century constitute a structural break in material resource use and inequality. Our findings lead us to conclude that in order to tackle the most challenging of environmental problems, we must fundamentally revise the common narrative about the compatibility of sustainable resource use and affluence.
\end{abstract}

Keywords: material use; material intensity; efficiency; affluence; inequality decomposition 


\section{Introduction}

Annual global material resource consumption increased by more than 20 billion tons between 2000 and 2010. This growth in just one decade was unprecedented - between 1950 and 2000, global material consumption had risen by between 6.5 and 7.5 billion tons per decade (Schaffartzik et al., 2014). The "Great Acceleration" of resource use and environmental degradation during the second half of the $20^{\text {th }}$ century (Steffen et al., 2015) experienced an additional boost in the $21^{\text {st }}$ century. In light of the far-reaching and largely irreversible environmental damage associated with the increasing consumption of resources - deforestation, biodiversity loss, anthropogenic climate change, and peak minerals, for example - these developments are troubling. In order to curb societal impact on the environment, absolute reductions of resource use are necessary (Akenji et al., 2016). Global resource use, however, is the result of vastly different per capita levels of resource use at the regional, the national, and the subnational level. Half of the global population in 2010 lived in countries that consumed only one quarter of global resources. In countries with low to very low levels of per capita resource consumption, physical growth is necessary in order to meet important societal goals. UN Sustainable Development Goals such as ending poverty and hunger or securing access to energy (United Nations, 2015) have material prerequisites. Infrastructure development comes at the cost of significant increases in carbon emissions (Müller et al., 2013). In order to attain environmental sustainability and ensure a more equitable future, a reduction of global resource use must be achieved. Per capita resource use must converge at a significantly lower level than what the world's richest countries are currently experiencing, i.e., resource use in some countries must contract. In policy debates, such development is commonly referred to as contraction and convergence (Schandl et al., 2017) ${ }^{1}$.

\footnotetext{
${ }^{1}$ The contraction and convergence mechanism for questions of resource use was initially proposed to combat anthropogenic climate change and provide the basis for an international climate treaty within the UN Framework Convention of Climate Change (Meyer, 1999).
} 
Contraction and convergence provides a solution to the problem of unequal distribution of high global levels of resource use. It is not, however, necessarily attractive: Political and economic actors may consider reductions of or limits to resource use to obstruct development opportunities (Akenji and Bengtsson, 2014). Because these perceived opportunities commonly boil down to possibilities for economic growth, resource efficiency has come to play a prominent role (UNEP, 2016, 2011), for example, in the European Union (European Commission, 2011), in China (West et al., 2013), and Japan (Hashimoto et al., 2008). Resource efficiency describes the amount of societally desired output - most commonly expressed as GDP - generated per unit of resource use. If resource efficiency improves, more economic prosperity can be attained without increasing overall resource use. Ideally, efficiency improvements are so strong that they allow for increasing wealth and decreasing resource use (UNEP, 2011), forming the basis for approaches to sustainability proposing that output must exceed input by a factor of x (Angrick et al., 2013; von Weizsäcker et al., 1997). Cornerstone possibilities for developments underlying resource efficiency improvements include GDP increasing more strongly than resource use (weak sustainability, see Victor et al. (1998)), 'off-shoring' of resource-intensive production steps (Wiedmann et al., 2015), decreased consumption, or a change in consumption patterns to favor less resource-intensive industries (Hoekstra and van den Bergh, 2002). Technological progress and its implementation in key producing industries may be an important factor in the efficiency gains at the aggregate national level considered here. Efficiency alone, however, does not suffice to achieve much-needed absolute reductions in resource use (Akenji et al., 2016). Global data have shown that while material productivity improves by a long-term annual average of $0.9 \%$, economic growth averages at 2.9\% (Krausmann et al., 2009). Under these conditions, global economic growth cannot be sustained.

Politically, contraction, convergence, and resource efficiency merge into a single storyline: International convergence of per capita resource use below the currently high level of industrial countries can lead to stabilization and reduction of global resource use. The limited physical 
growth opportunities can be counter-balanced by improved efficiency in order to safeguard economic prosperity and growth. In the context of this article, we refer to this scenario as one of efficient contraction and convergence. We do not suggest that contraction and convergence made politically viable through efficiency ${ }^{2}$ is the way to attain much-needed reductions in global resource use. Instead, we are interested in whether progress towards reduced resource use has been made on this potentially popular path.

The contributions of different drivers of growth have been analyzed by applying the I=PxAxT relation, expressing environmental impact $(I)$ as the product of population $(P)$, affluence $(A)$, and technology (T) (Ehrlich and Holdren, 1971). Material use - the particular type of resource use examined in this study - is an important driver of environmental change (Steinberger et al., 2010). Changes in biomass extraction and consumption, for example, are associated with land use change, biodiversity loss and carbon flows. Fossil energy carriers are associated with environmental impact during their extraction and especially with the emission of greenhouse gases when they are combusted. Metals, like fossil energy carriers, are subject to scarcity of supply and may be very energy-intensive in their extraction and concentration. Construction minerals make up the largest share in global material consumption. While their relative environmental impact may be low, the sheer size of this flow makes it relevant for sustainable resource use and extraction is associated with land degradation, biodiversity loss and groundwater depletion (Ashraf et al., 2011). However, their main contribution to global environmental change may lie in the further material and energy requirements associated with their integration into societal stocks (Müller et al., 2013). Material use can be considered a proxy for environmental pressure rather than a direct representation of impact. When I is interpreted as material use, affluence A as per capita GDP,

\footnotetext{
${ }^{2}$ Especially in light of the rebound effect (Alcott, 2005; Binswanger, 2001), we do not propose that efficiency improvements alone can lead to resource use contraction (see, e.g., Jackson, 2016).
} 
and technology $\mathrm{T}$ as material intensity ${ }^{3}$, important insights on groups of drivers of global environmental change can be gained (e.g., Schandl and West, 2010). The relative contribution of the $\mathrm{P}, \mathrm{A}$, and $\mathrm{T}$ factors can be assessed, most commonly through decomposition analysis. $\mathrm{A}$ recently published global study (UNEP, 2016) found affluence to be the most important driver of material growth, followed by population. While material intensity improvements generally played an important role in reducing material use throughout the $20^{\text {th }}$ century, during the first decade of the $21^{\text {st }}$ century increasing material intensity acted as a driver of material growth. Between 2000 and 2010 , global DMC increased by $43 \%$, over half of which (29\%) is attributed to increasing affluence and $13 \%$ to population growth. The technological coefficient (material intensity) that had curbed DMC growth since 1970 contributed 1\% to DMC growth. Material intensity increased in particular in the key exporting regions of West Asia and Latin America and the Caribbean (UNEP, 2016). International trade patterns (Giljum and Eisenmenger, 2004) include linkages between countries of high and low material intensity of production. In 2010 , high-income countries had the highest net-imports of all income-based country groupings. While middle-income countries mainly delivered the corresponding imports, low-income countries featured relatively small trade flows (Schaffartzik and Pichler, 2017).

In studying the scenario of material efficient contraction and convergence, we consider per capita levels of resource use (as that variable which must decrease internationally but may increase in some countries) as they result from resource efficiency and affluence at the national level. By examining international inequality (Druckman and Jackson, 2008) we seek to identify whether convergence of resource use levels is occurring. We do not consider absolute levels of global

\footnotetext{
${ }^{3}$ Material intensity is the inverse of material efficiency and indicates the amount of material use necessary to generate one unit of GDP. When material intensity increases, material efficiency decreases. For the analysis conducted in this study, it was necessary to consider intensity rather than efficiency (see section 2).
} 
resource use in depth. The magnitude of past and present global environmental change has been impressively demonstrated (Steffen et al., 2015), and we focus on a nuanced approach to nationallevel contributions to global development (Pichler et al., 2017).

We cover material use as a particular form of resource use. Internationally standardized and harmonized economy-wide material flow accounting (Krausmann et al., 2017a) provides data on material extraction, imports, exports allowing for the calculation of the headline indicator domestic material consumption (DMC = extraction plus imports minus exports). DMC is commonly used to calculate material efficiency as DMC/GDP. DMC can be described as a production-based indicator of material use. It accounts for all materials that are extracted within an economy for further use (domestic extraction), that enter the economy as imports, and that exit the economy as exports, wastes, or emissions (Fischer-Kowalski et al., 2011). DMC reflects the materials available to an economy for consumption or integration into in-use stocks of manufactured capital; it is a measure of the materials used or accumulated. DMC does not consider for what purpose material flows or stocks are used. This question of purpose is relevant, for example, in light of internationally increasing material trade flows (Schaffartzik et al., 2014). Methods for the calculation of so-called material footprints (e.g., Wiedmann et al., 2015) are currently being developed to consider the amount of material used for the production of exports (and hence not used to satisfy domestic final demand). These upstream material requirements include the mass of the trade flows crossing the border and additionally allocate material used in the production of exports but not incorporated in the flow itself. The material footprint measures the amount of materials that have been used in providing final consumption. Accounting for upstream material requirements currently relies on approximations via monetary input-output data which reflect the structure of production and consumption (Wiedmann et al., 2011). Monetary final demand of a country is a factor in the calculation of its material footprint and a component of GDP so that the two indicators are not 
independent (Schaffartzik et al., 2015) ${ }^{4}$ with according implications for the possibilities of statistical analyses. For our study, we required an indicator of material use that is statistically independent of GDP and takes a production-perspective. We therefore used the DMC indicator.

We studied a sample of approximately 100 countries between 1960 and 2010, analyzing metabolic rates, material intensity, and affluence. A country's metabolic rate is its per capita DMC (FischerKowalski et al., 2011). Material intensity is measured as DMC per unit of GDP and constitutes the inverse of a common measure of material efficiency (UNEP, 2011) - throughout this article, we will use the term "efficient" to refer to this type of aggregate, national or global relationship between two macro-indicators. Under this terminology, the more material a country consumes per unit of GDP generated, the less efficient it is. As affluence, we consider per capita GDP. We decompose metabolic rates into material intensity and affluence, probing whether improved resource efficiency is enabling stable or even lower metabolic rates even as affluence increases. We apply techniques of inequality measurement in order to examine international contraction in metabolic rates and the role that the development of material intensity and affluence have played therein.

\section{Material and methods}

Our analysis is based on national material consumption (DMC), income (GDP), and population data between 1960 and 2010 in 10-year-intervals extracted from the Global Metabolic Transition (GLOMETRA) project database maintained at the Institute of Social Ecology, Vienna (Schaffartzik et al., 2014). Due to the comparatively long time period studied, which includes, for example, the

\footnotetext{
${ }^{4}$ If material intensity is calculated based on the material footprint (MF) as MF/GDP, then domestic monetary final demand is simultaneously a factor in the numerator and an addend in the denominator. The impact on material intensity based on MF needs to be clarified before the type of analysis which we conduct can be applied.
} 
dissolution of the Soviet Union and of Yugoslavia, the number of countries for which data are available changes from one year to the next. In order ensure statistical consistency, we treated all countries as single observations. For example, the independent countries that emerged from the dissolution of the Soviet Union were considered as an aggregate even after 1990. Under the conventions of material flow accounting, it is possible that countries exhibit negative DMC values for individual years. This may be due to the fact that material extracted or imported during the previous year (and temporarily stockpiled) is exported during the year under observation, without a corresponding input-flow. The analysis we conducted required positive input variables, and we had to exclude countries that exhibited negative DMC values in any of the material categories. From 177 countries included in the GLOMETRA database, we studied 94 countries between 1960 and 2010 and additionally analyzed the 2010 data for a slightly larger sample of 116 countries (with the successor states of the Soviet Union and Yugoslavia as individual observations). For 2000-2010, we obtained highly similar results from both samples. Our country sample accounted for at least $97 \%$ of global material consumption at each point in time. Material flow data covers domestic extraction, imports, and exports by 65 materials and material groups. For the analysis presented here, we calculated per capita metabolic rates (DMC/cap), material intensity (DMC/GDP), and affluence (GDP/cap), using Maddison's (2010) Historical Statistics for the World Economy on population and GDP in constant 1990 Geary-Khamis dollars. In this measure of GDP, different currencies are expressed in terms of their purchasing power parity (PPP) compared to the US dollar. The choice of representation of GDP is relevant for the interpretation of our results, especially with regard to our study of international inequality. GDP expressed in PPP currency units has been found to be more equally distributed than GDP converted by market exchange rates (MER) (Steinberger et al., 2010; Wade, 2011). By using GDP in PPP units, we may be obtaining lower results for international inequality in affluence than we would based on GDP in MER. With regard to material productivity, it has been observed that the positive correlation with 
income is stronger for GDP in MER than in PPP (Steinberger et al., 2010). Both of these characteristics are conducive to our investigation.

Logarithmically approximated growth in metabolic rates can be decomposed into growth of per capita affluence and growth of material intensity (also see equation (2)). In addition, we required an approach to analyzing the international distribution of material consumption and its development over time. A well-known procedure for the analysis of distribution is that of inequality based on Lorenz curves and Gini coefficients. This approach has been applied to material use indicators by Steinberger et al. (2010). Options to measure inequality in international distribution which may be applied to material use have been reviewed by Duro (2012). For our particular application, we selected the Theil index (Theil, 1967) which allows for two types of decomposition: First, the decomposition of the metabolic rate into material intensity and affluence, second, the distinction of the role played by different groups (in our case: groups of countries) in the observed international inequality (Shorrocks, 1984).

In its application to the per capita material consumption or metabolic rate $(c)$ of $n$ countries, the Theil index is defined as:

$$
T(c)=\sum_{i=1}^{n} p_{i} * \ln \left(\frac{\mu}{c_{i}}\right)
$$

where $p_{i}$ is the share of country $i$ in the total population of our sample of countries, $\mu$ is the average metabolic rate of the sample, and $c_{i}$ is the per capita material consumption of country $i$. In is the natural logarithm. The Theil index is, by definition, always larger than zero. Its maximum value depends on the sample but typically (for large samples and normal distribution), a value higher than 1 is indicative of high inequality (Cowell, 2011). The Theil index is especially sensitive to changes at the bottom of the distribution, i.e., changes in material consumption in countries with very low metabolic rates have a stronger impact on the Theil index than changes in highconsuming countries. A simple example demonstrating this sensitivity is available in the supplementary material. 
A key advantage of the Theil index is the option of decomposing the main variable into its multiplicative factors (applied to carbon dioxide emissions, for example, by Duro et al., 2016; Duro and Padilla, 2006). This allows us to study the role of material intensity and affluence in shaping the metabolic rate:

$$
c_{i}=\frac{D M C_{i}}{P_{i}}=\frac{D M C_{i}}{G D P_{i}} * \frac{G D P_{i}}{P_{i}}=m_{i} * y_{i}
$$

Metabolic rate $c_{i}$ is defined as the DMC divided by the population of country $i\left(D M C_{i} / P_{i}\right)$. This fraction can also be expressed as the product of material intensity $\left(m_{i}=D M C_{i} / G D P_{i}\right)$ and affluence $\left(y_{i}=G D P_{i} / P_{i}\right)$. Growth in the metabolic rate may be the result of growth in material intensity or in affluence or of a combination of both factors. Conversely, improvements in material intensity and/or lower affluence can lead to lower metabolic rates.

By decomposing the Theil index of the metabolic rate into its multiplicative factors, we obtain information on the contribution of the development of material intensity (and affluence) to international disparities in per capita material consumption. In order to decompose the Theil index, we define two hypothetical vectors of metabolic rates each of which is calculated by allowing only one of the multiplicative factors (material intensity or affluence) to diverge from the sample mean:

$$
\begin{gathered}
c_{i t}^{m}=m_{i t} * y_{t} \\
c_{i t}^{y}=m_{t} * y_{i t}
\end{gathered}
$$

The vector described in equation 3a contains the metabolic rates for all countries calculated from country-specific material intensity $\left(m_{i t}\right)$ and average affluence $\left(y_{t}\right)$. Vector $3 \mathrm{~b}$ contains metabolic rates based on average material intensity $\left(m_{t}\right)$ and country-specific affluence $\left(y_{i t}\right)$.

For each of the factors $m$ and $y$, the Theil index, measuring contribution to international inequality of the metabolic rate, can now be computed. It has been demonstrated (Duro and Padilla, 2006) 
that the overall Theil index (here: $T(c))$ can be expressed as the sum of indices for $m$ and $y(T(m)$ and $T(y))$ and an interaction term:

$$
T(c)=I(m)+I(y)+\log \left(1+\frac{\sigma_{m, y}}{c_{t}^{m}}\right)
$$

The interaction term is the logarithm of one plus the population-weighted covariance between material intensity and affluence $\left(\sigma_{m, y}\right)$ divided by the average metabolic rate as would result from the vector described in $3 a$.

Equation 4 allows us to perfectly decompose overall inequality in metabolic rates into two indices that capture the partial contribution of each multiplicative factor and an interaction term representing the interfactorial correlation. If this interaction term, as derived from equation 4 , is negative, it means that countries with lower income would tend to have higher material intensities.

The Theil index offers an additional possibility for decomposition relevant to the object of our study: It can be broken down to reflect to which extent the observed inequality is caused by inequality between or within specific country groupings (Shorrocks, 1984). In the following, we will refer to these two components as $T_{B}$ (index of inequality between groupings) and $T_{W}$ (index of inequality within groupings). The overall Theil index $T$ is the sum of $T_{B}$ and $T_{W}$. This distinction has analytical merit in allowing us to assess the explanatory power of commonly used sub-global regions or country groupings in analyses of international development. This decomposition of the Theil index for the metabolic rate takes the following functional form for $\mathrm{G}$ groups of countries:

$$
T(c)=\sum_{g=1}^{G} p_{g} T(c)_{g}+\sum_{g=1}^{G} p_{g} \ln \left(\frac{\mu}{c_{g}}\right)
$$

Here, $p_{g}$ is the weight of group $g$ in global population and $T(c)_{g}$ denotes inequality of metabolic rates within group $\mathrm{g}$. The natural logarithm $\mathrm{In}$ is taken of the sample average metabolic rate $\mu$ (as in equation 1) is divided by the group average metabolic rate $c_{g}$. The within-group component $T_{W}$ is the Theil index (see equation 1) while the between-group component $T_{B}$ is the populationweighted average of the Theil indices of each of the groups (Duro and Padilla, 2006). 
The calculations are, as we have shown, population-weighted: Countries have greater or lesser influence on overall inequality and on the decomposition result according to their population size. As the object of our study is per capita material consumption, this weighting is analytically consistent but must nonetheless be taken into account in interpreting the results. Large, resourcerich countries with comparatively small population tend to feature very high levels of per capita material consumption (e.g., Australia, Canada). If our analysis were not population-weighted, such countries could have a strong impact on the overall results. In our interpretation of the Theil index results, we also consider the limitations of the model on which our decomposition is based: By expressing metabolic rates as the product of material intensity and affluence, we exclude many potentially decisive - factors influencing per capita material consumption from our analysis. We do not wish to dismiss the role of such factors (e.g., climate, topography, culture, economic structure) but to focus on those two factors crucial for testing for 'efficient contraction and convergence'.

To illustrate the shape of the distribution of metabolic rates, we construct continuous density functions for selected years through Gaussian kernel estimates with an optimal smoothing parameter. Since the density functions are continuous, the frequency of any variable is not bound to 1 and can be interpreted as the probability of that variable assuming a value within a specific range ${ }^{5}$.

Finally, we were also interested in the role that different material types (biomass, fossil fuels, ores, and non-metallic minerals) play in inequalities of metabolic rates. Shorrocks (1982) proposes an additive decomposition technique which we applied ${ }^{6}$. This method, referred to in the literature as

\footnotetext{
${ }^{5} \mathrm{~A}$ discrete function could be interpreted as frequencies of variables corresponding to probabilities of variables assuming a certain value.

${ }^{6}$ In environmental analysis, this method has been used, for example, by Teixidó-Figueras and Duro (2015).
} 
decomposition by source, allows the contribution of each material type to be expressed in terms of its individual variance (direct contribution) and also of interfactorial covariance (indirect contribution). Specifically, the contribution $C_{k}$ of each material $k\left(M_{k}\right)$ is approximated by the following formulation:

$$
C_{k}=\frac{\operatorname{Var}\left(M_{k}\right)+\sum_{j \neq k} \operatorname{Cov}\left(M_{k}, M_{j}\right)}{\operatorname{Var}(M)}=\sum_{j} \operatorname{Cov}\left(M_{k}, M_{j}\right)=\operatorname{Cov}\left(M_{k}, M\right)
$$

The relative weight of each material in terms of overall inequality would be a result of its own concentration, of the relative weight of the material as part of the overall annual demand, and of its correlation with other materials.

\section{Results}

\subsection{The world between 1960 and 2010: More material use and even more wealth}

Since 1960, global material resource consumption (factor 3.7) and GDP (factor 6.4) have grown more strongly than world population (factor 2.3). The average metabolic rate increased from 6.4 tons per capita (t/cap) in 1960 to 10.3 t/cap in 2010 (factor 1.6, see Figure 1) while affluence increased by a factor of 2.8 from approximately 2700 constant 1990 international Geary-Khamis dollars (GK\$) per capita to 7600 GK\$/cap. During this 50-year period, material intensity decreased from 3.2 kilograms per GK\$ to $1.8 \mathrm{~kg} / \mathrm{GK} \$$ : In 2010 , less than $60 \%$ the amount of material was required to generate one unit of GDP compared to 1960. At this aggregate level and across the entire period of time, our three focal indicators suggest that efficiency improvements enabled higher levels of wealth without causing proportional increases in material use. Whether the increasing metabolic rate signals greater international equality in material use is a question to which we will return. Even without further analysis, a striking change of trend becomes visible in Figure 1: The decade from 2000 to 2010 is characterized by accelerated growth in affluence and the metabolic rate and by a deceleration in the decline of material intensity. Following a period of 
relatively stable metabolic rates between 1980 and $2000(+0.1 \mathrm{t} / \mathrm{cap})$, more than $60 \%$ of the overall growth of $3.9 \mathrm{t} /$ cap occurred during the last decade alone. Affluence experienced almost $40 \%$ of its overall growth between 2000 and 2010 . Material intensity remained almost unchanged between $2000(1.38 \mathrm{~kg} / \mathrm{GK} \$)$ and $2010(1.36 \mathrm{~kg} / \mathrm{GK} \$)$.

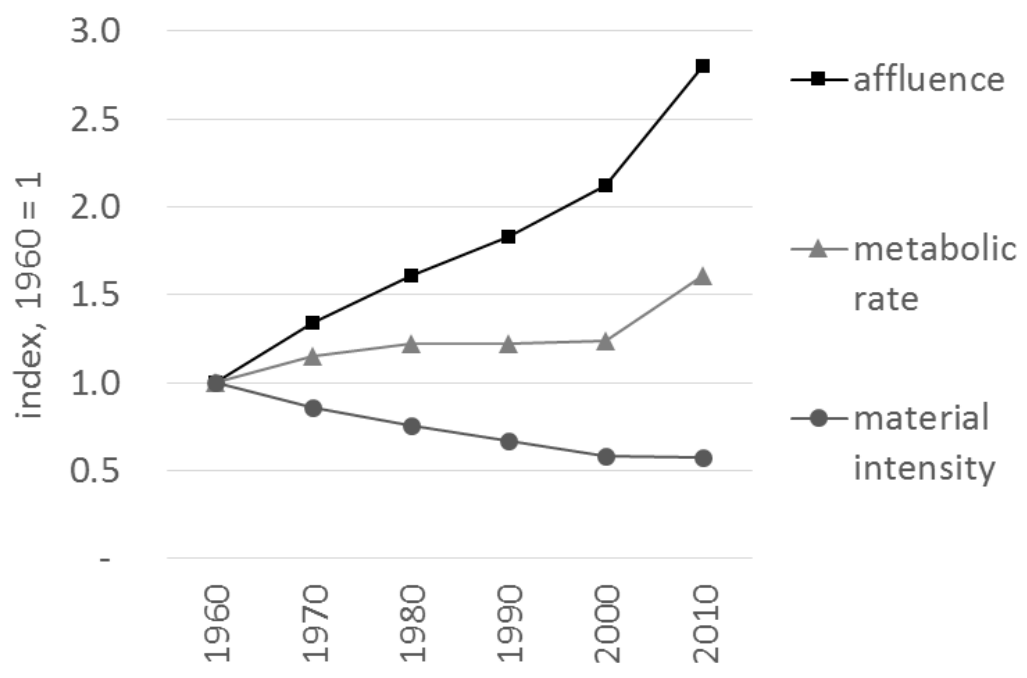

Figure 1: Trends in world average affluence (GDP/cap), metabolic rate (material consumption DMC/cap), and material intensity (DMC/GDP) between 1960 and 2010. Source of data: Schaffartzik et al. (2014)

Between 1960 and 2010, income (GDP) grew to such an extent that it offset efficiency gains - the metabolic rate increased. A simple logarithmic decomposition of the metabolic rate as the product of material intensity and affluence (equation 2) supports this interpretation. In the individual decades as well as over the 50 -year period as a whole, the metabolic growth rate was the result of opposite behavior of its two components (Table 1): Material intensity decreased but affluence grew so strongly that it 'overcompensated' any efficiency gains. Economic growth explains the growth in metabolic rates. If material intensity had not simultaneously decreased, the growth in material consumption would have been much higher. Between 1980 and 1990, for example, average per capita material consumption stagnated $(+0.5 \%)$ because the decrease in material intensity $(-12.6 \%)$ was almost balanced by the increase in affluence $(+13.1 \%)$. 
The growth in the global metabolic rate $(+26.5 \%)$ from 2000 to 2010 is unprecedented and accompanied by a very high increase in affluence $(+27.9 \%)$. In order to 'compensate' such levels of economic growth, material efficiency would have to be greatly improved. Instead, however, a comparatively slight decrease in material intensity only marginally caused reduction of material use $(-1.5 \%)$.

\begin{tabular}{|rrrr|}
\hline & $\begin{array}{r}\text { Metabolic } \\
\text { Rate (c) }\end{array}$ & $\begin{array}{r}\text { Material } \\
\text { Intensity (m) }\end{array}$ & $\begin{array}{r}\text { Affluence } \\
\mathbf{( y )}\end{array}$ \\
\hline $1960-1970$ & $14.0 \%$ & $-14.9 \%$ & $29.0 \%$ \\
$1970-1980$ & $5.4 \%$ & $-13.0 \%$ & $18.5 \%$ \\
$1980-1990$ & $0.5 \%$ & $-12.6 \%$ & $13.1 \%$ \\
$1990-2000$ & $1.6 \%$ & $-13.7 \%$ & $15.3 \%$ \\
$2000-2010$ & $26.5 \%$ & $-1.5 \%$ & $27.9 \%$ \\
\hline $1960-2010$ & $48.0 \%$ & $-55.7 \%$ & $103.7 \%$ \\
\hline
\end{tabular}

Table 1: Factorial decomposition of metabolic rates growth, selected periods 1960-2010. Source of data:

Schaffartzik et al. (2014)

\subsection{A sub-global perspective reveals differences in trends}

In order to investigate the particular contributions of individual countries to the global averages, we performed a logarithmic decomposition of the metabolic growth rate by 11 geographic regions and by 4 economic country groupings ${ }^{7}$ (Table 2). The economic country groupings are based on

\footnotetext{
${ }^{7}$ We additionally analyzed a third country classification which consisted of six major country groupings based on economic as well as geographic attributes (see Schaffartzik et al., 2014). However, we found that for this classification, especially from 2000 onwards, the international inequality in metabolic rates on which our investigation focuses is better explained by differences within than by differences between the country groupings. We found the 11 geographic regions
} 
the income thresholds (high, upper-middle, lower-middle, low) for per capita gross national income in 2010 defined by the World Bank (2016). A list of the countries included in each of the groupings is provided in the supplementary material. From this sub-global perspective, three key aspects of the growth in metabolic rates are remarkable.

1) The decade of highest growth in global metabolic rates is also the decade of declining metabolic rates in the high-income countries. The high-income countries as well as the geographic regions into which these countries primarily fall (Western Europe, Northern America, and Oceania \& Australia), experienced a reversal of the metabolic growth rate from 2000 to 2010 as compared to the entire 50-year-period. From 1960 to 2010, metabolic rates grew while from 2000 to 2010 , the values of this indicator decreased. Average affluence increased more strongly than could be compensated by efficiency improvements. From 2000 to 2010, material intensity became the more powerful explanatory variable for the metabolic rate of high-income countries and efficiency gains were able to offset economic growth.

2) From 2000 to 2010 , declining metabolic rates in the high-income countries coincide with increasing material intensity and increasing material use in other regions and income groupings. Aside from the high-income countries, all other economic country groupings experienced growth in their metabolic rates from 1960 to 2010 , including the last decade. This is also true for the geographic regions in which the middle- and low-income countries are primarily located. In general, this increase in metabolic rates is due to affluence growing more strongly than material efficiency. From 2000 to 2010, however, material intensity caused metabolic rates to rise in Latin America and the Caribbean, Northern Africa and West Asia, and Eastern Asia. These regions encompass the middle-income countries are key net-exporters and origins of the high net-imports of the high-income countries (Schaffartzik and Pichler, 2017). Decreasing metabolic rates and

to be more appropriate for our analysis across the whole period of time (also see supplementary material). 
improving material efficiency in the high-income countries cannot be understood independently of increasing material use and rising material intensity in middle-income countries.

3) The path to higher income may be material-intensive. Within the income-based country groupings, we observe a progression from low- to middle-income countries associated with stronger growth in the metabolic rate and, from 2000-2010, a declining balancing effect of material efficiency. This trajectory does not include the high-income countries but if the path from low to high income leads via high levels of material consumption and material intensity, then it is not a globally sustainable form of development. Even among the high-income countries, no evidence for long-lasting absolute reductions in material use exists ${ }^{8}$, further leading us to question whether development toward high-income is compatible with much-needed material use contraction at the global level.

\footnotetext{
${ }^{8}$ Some high-income countries have exhibited decreasing material consumption since the
} $2007 / 2008$ crisis but data are not yet available to assess the longevity of this trend. 


\begin{tabular}{|c|c|c|c|c|c|c|c|}
\hline & \multicolumn{3}{|c|}{$1960-2010$} & \multicolumn{3}{|c|}{ 2000-2010 } \\
\hline & & c & $\mathrm{m}$ & $\mathrm{y}$ & c & $\mathrm{m}$ & $y$ \\
\hline \multirow{11}{*}{ 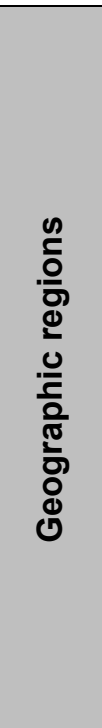 } & Western Europe & $17 \%$ & $-95 \%$ & $112 \%$ & $-13 \%$ & $-21 \%$ & $8 \%$ \\
\hline & Northern America & $2 \%$ & $-100 \%$ & $102 \%$ & $-18 \%$ & $-25 \%$ & $7 \%$ \\
\hline & Oceania\&Australia & $13 \%$ & $-84 \%$ & $97 \%$ & $-8 \%$ & $-22 \%$ & $14 \%$ \\
\hline & LACA & $48 \%$ & $-35 \%$ & $83 \%$ & $20 \%$ & $0 \%$ & $19 \%$ \\
\hline & Eastern\&SE Europe & $34 \%$ & $-76 \%$ & $110 \%$ & $20 \%$ & $-27 \%$ & $47 \%$ \\
\hline & Subsaharan Africa & $-30 \%$ & $-71 \%$ & $41 \%$ & $2 \%$ & $-28 \%$ & $30 \%$ \\
\hline & Northern Africa\&West Asia & $75 \%$ & $-36 \%$ & $111 \%$ & $29 \%$ & $3 \%$ & $26 \%$ \\
\hline & Central Asia \& USSR & $6 \%$ & $-62 \%$ & $68 \%$ & $24 \%$ & $-32 \%$ & $56 \%$ \\
\hline & Southern Asia & $43 \%$ & $-97 \%$ & $141 \%$ & $23 \%$ & $-28 \%$ & $51 \%$ \\
\hline & Eastern Asia & $178 \%$ & $-45 \%$ & $223 \%$ & $73 \%$ & $6 \%$ & $67 \%$ \\
\hline & Southeastern Asia & $65 \%$ & $-91 \%$ & $157 \%$ & $35 \%$ & $-5 \%$ & $41 \%$ \\
\hline \multirow{4}{*}{ 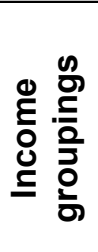 } & Low Income & $-6 \%$ & $-74 \%$ & $69 \%$ & $20 \%$ & $-31 \%$ & $50 \%$ \\
\hline & Lower-Middle Income & $40 \%$ & $-90 \%$ & $130 \%$ & $23 \%$ & $-21 \%$ & $44 \%$ \\
\hline & Upper-Middle Income & $101 \%$ & $-43 \%$ & $144 \%$ & $57 \%$ & $-7 \%$ & $64 \%$ \\
\hline & High Income & $22 \%$ & $-96 \%$ & $118 \%$ & $-13 \%$ & $-23 \%$ & $10 \%$ \\
\hline
\end{tabular}

Table 2: Factorial decomposition of metabolic rates growth (c) into growth of material intensity $(\mathrm{m})$ and of affluence $(y)$ for geographic regions and income groupings for the 50-year period from 19602010 and the decade 2000-2010. The overall change in c during each of the time periods corresponds to the sum of the change caused by $\mathrm{m}$ and the change caused by $\mathrm{y}$. Source of data: Schaffartzik et al. (2014)

Our analysis of geographic regions and country groupings highlights the relevance of income. We therefore return to the income-based country groupings in our investigation of inequality (section 3.6).

\subsection{Growing inequality in metabolic rates}

The sub-global decomposition of the growth in metabolic rates in Table 2 very clearly demonstrates that international development with regard to material use, material intensity, and affluence is not homogenous. For example, we observe significantly less growth in material use in low- and lower-middle- than in upper-middle-income countries, and growth in metabolic rates 
varies strongly geographically. Our results for regions and groupings do not suggest international convergence of metabolic rates. Each of the curves in Figure 2 represents the international distribution of metabolic rates in a particular year between 1960 and 2010 . For the first four points in time $(1960,1970,1980,1990)$, we find that the distribution is unimodal with one clearly identifiable peak between 0.4 and 0.5 : The majority of the global population uses material resources at a level that amounts to approximately half the global average metabolic rate. Emerging in 2000 and highly visible in 2010 is a second peak in what has become a bimodal distribution. In 2000, a concentration emerges at approximately the average global metabolic rate (1 on the x-axis) which by 2010 has shifted to the right so that there is now a second pole of material resource approaching double the global average. The international distribution of material use shows that, especially during the strong growth in global material use between 2000 and 2010, the distribution in per capita material use has become more unequal and more polarized. ${ }^{9}$ For our investigation, this has two very important implications: 1) Global averages are ill-suited to provide a full picture of the dynamics underlying the growth in global material resource use (and thus the inherent sustainability threat), and 2) The most pronounced global growth in material use is accompanied by bipolarization of metabolic rates, making it relevant to investigate potential links between these two trends.

\footnotetext{
${ }^{9}$ If we calculate an explicit index of bi-polarization between 2000 and 2010 as has been suggested by Foster and Wolfson (2010), for example, its value would increase from 0.27 to 0.42 .
} 


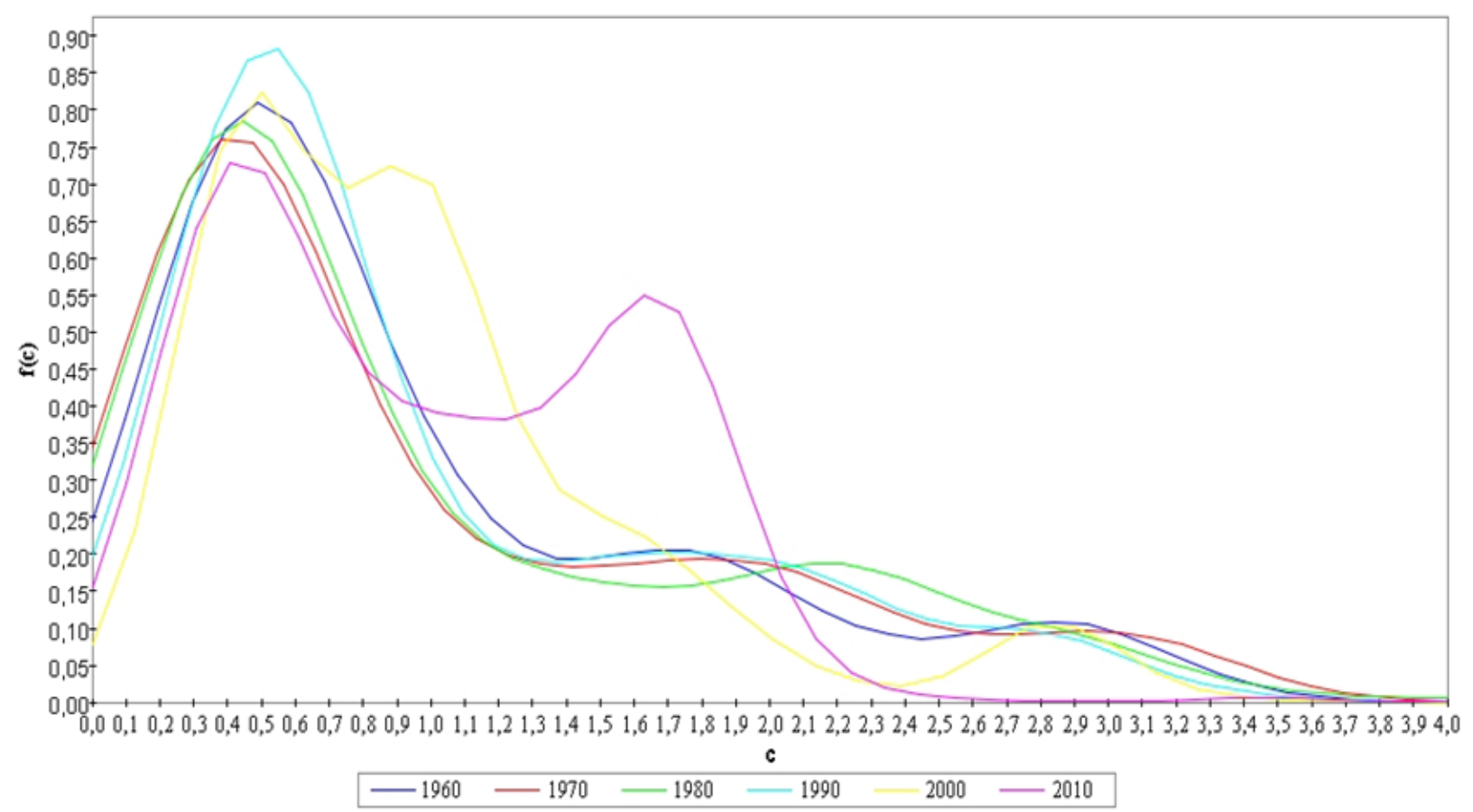

Figure 2: Comparing international metabolic rate distributions 1960-2010, kernel estimates. The values on the $y$-axis indicate the probability that the metabolic rate takes a value in a range with the metabolic rate indicated on the $x$-axis in relation to the sample average metabolic rate (e.g., $x$-value 0.5 indicates half the sample average rate). Source of data: Schaffartzik et al. (2014)

The narrative commonly used to explain growth in global resource use is that of the emerging (and eventually the developing) economies "catching up". If these countries were indeed developing towards an industrial metabolic rate, growth in global material use should coincide with decreasing international inequality. The results presented in Figure 2, however, suggest that the opposite may be the case and that, during the period of strong growth in global material use from 2000 to 2010 , inequality in metabolic rates no longer decreased. To explore this trend further, we factorized international inequality in metabolic rates using the Theil index (Table 3). From 2000 onwards, the Theil index of national metabolic rates remains relatively stable (at around 0.2 ) indicating that during this time of strong growth in global material consumption, inequality in metabolic rates no longer decreased. In explaining the inequality in metabolic rates, material intensity became increasingly important, its relative weight increasing from $43 \%$ in 1960 to $77 \%$ in 2010 . Although the impact of affluence on inequality in metabolic rates decreases (from $218 \%$ to $190 \%$ ), it 
continues to be a very important explanatory factor. The correlation factor between material intensity and income is negative, i.e., countries with relatively higher income tend to have relatively lower material intensity. The negative correlation value as well as its magnitude also indicate that the inequalities of one factor partially compensate for those of the other. Factorial inequalities $(\mathrm{I}(\mathrm{m})$ and $\mathrm{I}(\mathrm{y})$ ) indicate the direct and partial contribution of each factor while their correlation represents the indirect contribution, which reduces global inequality. Between 1960 and 2010, the absolute value of the interaction term is reduced although its relative weight is maintained.

\begin{tabular}{c|c|c|c|c|}
\multirow{2}{*}{1960} & $\mathbf{T}(\mathbf{c})$ & $\mathbf{I}(\mathbf{m})$ & $\mathbf{l}(\mathbf{y})$ & correlation \\
\cline { 2 - 5 } & \multirow{2}{*}{0.27} & 0.12 & 0.58 & -0.43 \\
\multirow{2}{*}{1970} & & $43 \%$ & $218 \%$ & $-162 \%$ \\
\hline \multirow{2}{*}{1980} & \multirow{2}{*}{0.34} & 0.11 & 0.67 & -0.45 \\
& & $33 \%$ & $201 \%$ & $-134 \%$ \\
\hline \multirow{2}{*}{1990} & \multirow{2}{*}{0.32} & 0.12 & 0.68 & -0.49 \\
& & $39 \%$ & $215 \%$ & $-154 \%$ \\
\hline \multirow{2}{*}{2000} & \multirow{2}{*}{0.25} & 0.12 & 0.61 & -0.49 \\
& & $49 \%$ & $245 \%$ & $-194 \%$ \\
\hline \multirow{2}{*}{2005} & \multirow{2}{*}{0.20} & 0.14 & 0.55 & -0.49 \\
& & $71 \%$ & $277 \%$ & $-248 \%$ \\
\hline \multirow{2}{*}{2010} & \multirow{2}{*}{0.20} & 0.15 & 0.46 & -0.41 \\
& & $72 \%$ & $231 \%$ & $-203 \%$ \\
\hline \multirow{2}{*}{0.20} & 0.16 & 0.38 & -0.34 \\
& & $77 \%$ & $190 \%$ & $-167 \%$ \\
\hline
\end{tabular}

Table 3: Factorial international inequality decomposition of metabolic rates, 19602010: Theil index of the metabolic rate (T(c)) decomposed into contribution of material intensity $\mathrm{I}(\mathrm{m})$ and of affluence $\mathrm{I}(\mathrm{y})$. Source of data: Schaffartzik et al. (2014)

While material intensity has become increasingly important in explaining inequality in metabolic rates, affluence has lost importance. To further explore the role of these two factors, we have studied the development of inequality in material intensity and affluence. The Theil index for material intensity and affluence shows that while, from 1970 to 2010 , inequality in affluence 
continuously decreased, inequality in material intensity increased (Figure 3). ${ }^{10}$ Material intensity has decreased strongly since 1960 (Figure 1, Table 1), but has become more unequally distributed. At the same time - as our analysis of geographic regions suggests - material intensity may have increased in particular in those countries that are important international suppliers of material. In this sense, the consumption in countries with decreasing material intensity may be tied to production in countries with increasing material intensity and thus to the global growth in material consumption. Decreasing inequality in affluence and increasing inequality in material intensity lead to both indicators reaching a comparable level of inequality in 2010.

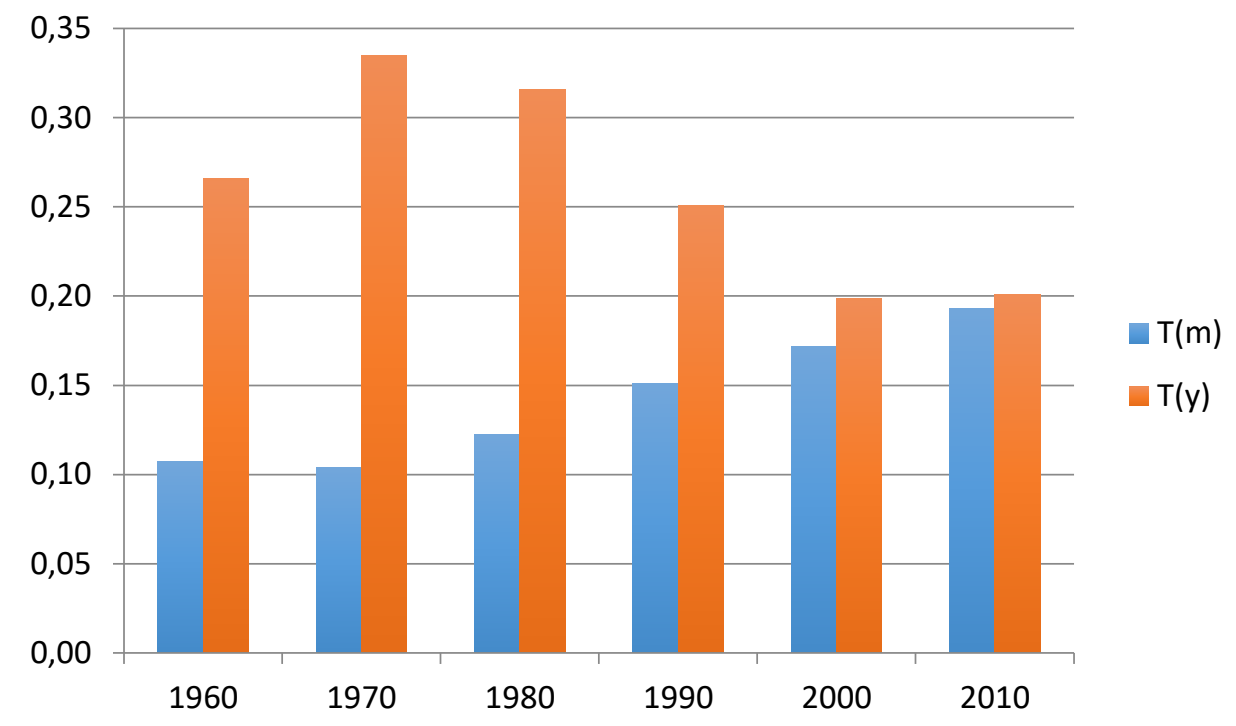

Figure 3: Evolution of inequality in material intensity $T(m)$ and affluence $T(y)$ between 1960 and 2010 as resulting from the Theil indices. Source of data: Schaffartzik et al. (2014)

By 2010 , material intensity has not only become an important explanatory variable in per capita material use, it has also become similarly unequal compared to affluence. Analyses of inequality

10 The development of the Gini index for material intensity is similar to the development of the Theil index: Between 1970 and 2010, the Gini index would have increased from 0.25 to 0.33 . 
that focus exclusively on inequality in wealth may be missing an important potential obstacle for a sustainability transition.

We have observed that 1) global average material intensity has been decreasing and 2) inequality in material intensity has ceased to decrease. The density function of the international distribution of material intensity (Figure 4) reveals a new pattern in material intensity by GDP. Between 1960 and 2010, the average material intensity of the group of countries which together account for the highest share of global GDP has shifted to the left, i.e., has decreased from around 0.7 to 0.5 . While the group of countries accounting for the majority of global GDP had a material intensity of approximately $2.2 \mathrm{~kg} / \mathrm{GK} \$$ corresponding to $70 \%$ of the global average in 1960 , their material intensity of approximately $0.9 \mathrm{~kg} / \mathrm{GK} \$$ corresponded to $50 \%$ of the global average in 2010 . In addition, a second pole in material intensity emerged at approximately $3.4 \mathrm{~kg} / \mathrm{GK} \$$ (almost double the global average in 2010). By 2010, the distribution of material intensity is clearly bipolarized, and the difference between the two poles has become extreme: In terms of GDP, there is one concentration of countries with a material intensity which corresponds to approximately half the global average and a second concentration of countries with a material intensity which is double the global average. 


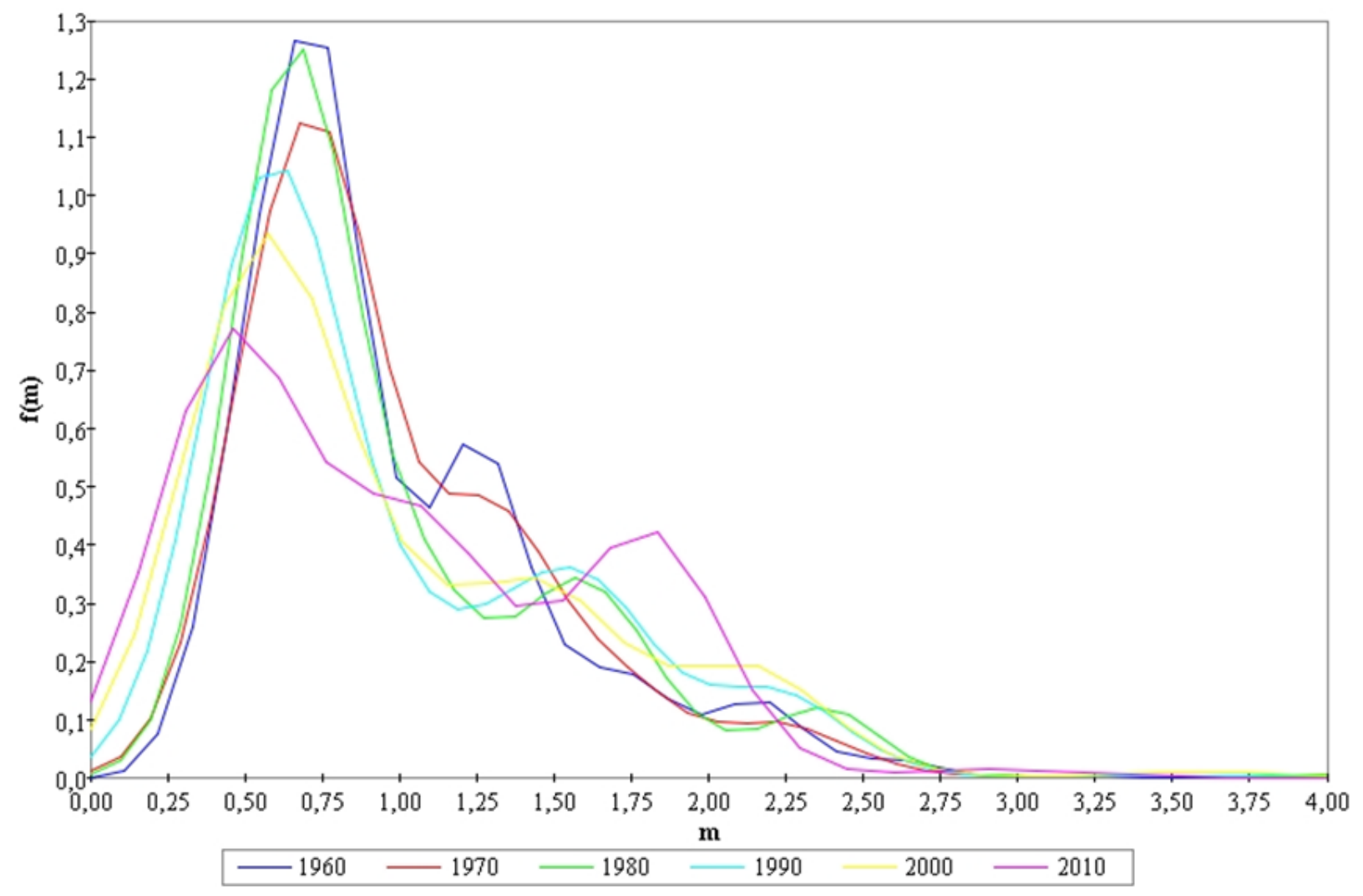

Figure 4: Comparing international material intensity distributions 1960-2010, kernel estimates. The values on the $y$-axis indicate the probability that the metabolic rate takes a value in a range with the metabolic rate indicated on the $\mathrm{x}$-axis in relation to the sample average metabolic rate (e.g., x-value 0.5 indicates half the sample average rate). Source of data: Schaffartzik et al. (2014)

\subsection{Constructing inequality: The role of different material groups}

Inequality in per capita material consumption is shaped not only by material intensity and affluence but also by the additive components of material consumption. Total material consumption is composed of different types of materials that, at a high level of aggregation, can be distinguished into biomass (extracted mainly through agriculture and forestry), fossil fuels (including petroleum, coal, and natural gas), metals, industrial minerals, and construction minerals such as sand and gravel used in bulk. Using Shorrocks (1982) decomposition, we find that by 2010, approximately $41 \%$ of the inequality in metabolic rates stemmed from the internationally different levels of use of construction minerals, followed by metals and fossil fuels (21\% each) and biomass (15\%) (Table 
$4)^{11}$. The contribution of these materials to global DMC plays a role in determining their influence on inequality but is not the only explanatory variable. The increase in global material consumption between 2000 and 2010 coincided with a strong increase in the contribution of construction minerals to global inequality from $22 \%$ to $41 \%$ while the share of construction minerals in global DMC increased by $7 \%$. Much of this change occurred in the second half of the decade (20052010) and during the financial crisis. During this time, the role of biomass, fossil fuels, and ores in explaining overall metabolic inequality diminished as did their share in DMC.

\begin{tabular}{|c|c|c|c|c|c|c|c|c|c|c|c|c|}
\hline & \multicolumn{2}{|c|}{ biomass } & \multicolumn{2}{|c|}{ fossil fuels } & \multicolumn{2}{|c|}{ ores } & \multicolumn{2}{|c|}{$\begin{array}{c}\text { industrial } \\
\text { minerals }\end{array}$} & \multicolumn{2}{|c|}{$\begin{array}{l}\text { construction } \\
\text { minerals }\end{array}$} & \multicolumn{2}{|c|}{ products } \\
\hline & ineq. & $D M C$ & ineq. & $D M C$ & ineq. & $D M C$ & ineq. & $D M C$ & ineq. & $D M C$ & ineq. & $D M C$ \\
\hline 1960 & $35 \%$ & $51 \%$ & $30 \%$ & $20 \%$ & $11 \%$ & $7 \%$ & $2 \%$ & $1 \%$ & $22 \%$ & $21 \%$ & $0 \%$ & $0 \%$ \\
\hline 1970 & $27 \%$ & $43 \%$ & $33 \%$ & $22 \%$ & $11 \%$ & $7 \%$ & $2 \%$ & $1 \%$ & $26 \%$ & $26 \%$ & $0 \%$ & $0 \%$ \\
\hline 1980 & $27 \%$ & $40 \%$ & $34 \%$ & $23 \%$ & $10 \%$ & $7 \%$ & $2 \%$ & $2 \%$ & $27 \%$ & $29 \%$ & $0 \%$ & $0 \%$ \\
\hline 1990 & $27 \%$ & $40 \%$ & $34 \%$ & $22 \%$ & $11 \%$ & $7 \%$ & $3 \%$ & $2 \%$ & $25 \%$ & $29 \%$ & $0 \%$ & $0 \%$ \\
\hline 2000 & $23 \%$ & $37 \%$ & $29 \%$ & $20 \%$ & $23 \%$ & $8 \%$ & $3 \%$ & $2 \%$ & $22 \%$ & $33 \%$ & $0 \%$ & $0 \%$ \\
\hline 2005 & $21 \%$ & $33 \%$ & $27 \%$ & $20 \%$ & $23 \%$ & $8 \%$ & $3 \%$ & $2 \%$ & $27 \%$ & $37 \%$ & $0 \%$ & $0 \%$ \\
\hline 2010 & $15 \%$ & $30 \%$ & $21 \%$ & $19 \%$ & $21 \%$ & $9 \%$ & $2 \%$ & $2 \%$ & $41 \%$ & $40 \%$ & $0 \%$ & $0 \%$ \\
\hline
\end{tabular}

Table 4: Decomposing inequalities in international metabolic rates (ineq. column) and share in DMC (DMC column) by materials categories (Shorrocks decomposition, decomposition by sources). Source of data: Schaffartzik et al. (2014)

Our analysis of inequality is based on the metabolic rate, i.e. on per capita material use. This means that China's fast growth in the use of construction minerals, especially between 2000 and 2010, is not the main explanation for the trend. At slightly over 10 tons per capita, China's

${ }^{11}$ Steinberger et al. (2010) used the Gini coefficient to study international inequality by material type, identifying the progression from least to most unequal distribution: biomass, construction minerals, fossil fuels, and ores and industrial minerals. Due to the different shares of each of these materials in total material consumption, their contribution to inequality in metabolic rates does not follow the same progression. 
construction mineral consumption in 2010 ranked $9^{\text {th }}$ in the world while, at the same time, absolute construction mineral consumption accounted for $50 \%$ of global consumption (Schaffartzik et al., 2014). The dominant role of construction minerals in inequality is especially driven by populous countries with high levels of construction activity; this is true of China as well as a number of other emerging economies (e.g. Brazil, Nigeria, Russia, Mexico).

Industrializing and emerging economies in particular are characterized by high construction mineral shares (around 50\%) in their total material use. Those countries that industrialized early, in contrast, tend to feature relatively equal shares of biomass, fossil fuels, and construction minerals at around $20-30 \%$ of total material consumption (Schaffartzik et al., 2014). Our results show that the role of construction minerals in metabolic inequality is not only statistically relevant but becoming increasingly important as global levels of material use increase. Construction minerals, used in bulk and bought and sold at comparatively low prices, are not nearly as wellunderstood in terms of their use patterns as are other types of materials (e.g., petroleum, types of metals). The research gap for construction activity as a driver of material use has been identified with regard to metals, for example, by Steger and Bleischwitz (2011). Our findings highlight the need to continue along the recently expanding research path on construction minerals, especially with regard to stock-flow relationships and the implications of current decisions for future material demand (Krausmann et al., 2017b; Pauliuk and Müller, 2014).

\subsection{Revisiting the income-based country grouping: How much explanatory power does it have?}

Finally, we wanted to know to whether the international inequalities we have identified are reflected in the common grouping of countries by level of affluence. We assessed how much of international inequality in metabolic rates could be explained by inequality between and within these groupings. Our prerogative is that if affluence levels have strong explanatory power with regard to metabolic 
rates, then the distinction between countries by affluence should correspond - to some degree to a distinction by metabolic rates. Differences between the income-based country groupings should explain a major share of international metabolic inequality, while the inequality within these groupings should be comparatively low.

We grouped countries by income for the entire period (1960-2010) based on their 2010 national income level. We chose such a static classification of countries (as opposed to countries belonging to different groupings at different points in time) because this approach enables us to study the development that allowed countries to reach or maintain a specific level of income in 2010. As a result of this decision, the income-based country groupings more accurately reflect differences in affluence in 2010 than in 1960. The fact that countries' performance with regard to income was dynamic during the period under investigation is reflected in the income-based country groupings' better suitability for the explanation of international inequality more recently than at the beginning of the period of investigation (Table 5): In 1960, differences between the groupings could explain $45 \%$ of international inequality. By 2005 , this share had significantly increased to $84 \%$. While differences within the groupings explained $55 \%$ of international metabolic inequality in 1960 , this share had dropped to $16 \%$. Considering that we have grouped almost 100 countries into just four income categories, the explanatory power of these categories is noticeably high. These results additionally confirm our findings on the important role of affluence as an explanatory variable for metabolic rates (Table 1). Between 2005 and 2010, we observe a slight drop in the Theil index for inequality between the country groupings (and a corresponding increase in the index for inequality within). While the explanatory reach of the income-based groupings remains high, it is interesting to note that it recedes in that year on which the classification was based (2010). This may point to the 2007/2008 economic crisis that had, in some cases drastic, impact on the material use levels, especially of some of the high-income countries. Metabolic rates may be more sensitive to economic crisis than income levels (within the relatively broad definition of high income according to the World Bank) - this possibility requires and merits further research. 
In spite of the fact that the country groupings are based on differences in affluence, we see our previous results on the increasing importance of material intensity in shaping metabolic inequality corroborated. For the inequality between and even more so for the inequality within the country groupings, differences in material intensity played a much more important role early in the $21^{\text {st }}$ century than they did throughout the second half of the $20^{\text {th }}$ century, while, even for these incomebased country groupings, the influence of affluence decreased. Nonetheless, affluence clearly remained the dominant explanatory variable.

\begin{tabular}{|c|c|c|c|c|c|c|c|c|}
\hline & Tb & $I(m)$ & I(y) & corr & Tw & $\mathrm{I}(\mathrm{m})$ & $\mathrm{I}(\mathrm{y})$ & corr \\
\hline \multirow{2}{*}{1960} & 0.12 & 0.06 & 0.36 & -0.30 & 0.15 & 0.05 & 0.22 & -0.12 \\
\hline & $45 \%$ & $47 \%$ & $300 \%$ & $-248 \%$ & $55 \%$ & $32 \%$ & $150 \%$ & $-82 \%$ \\
\hline \multirow{2}{*}{1970} & 0.18 & 0.05 & 0.43 & -0.30 & 0.16 & 0.05 & 0.24 & -0.14 \\
\hline & $53 \%$ & $28 \%$ & $240 \%$ & $-168 \%$ & $47 \%$ & $34 \%$ & $155 \%$ & $-90 \%$ \\
\hline \multirow{2}{*}{1980} & 0.18 & 0.06 & 0.45 & -0.32 & 0.14 & 0.06 & 0.24 & -0.16 \\
\hline & $57 \%$ & $32 \%$ & $247 \%$ & $-179 \%$ & $43 \%$ & $43 \%$ & $173 \%$ & $-116 \%$ \\
\hline \multirow{2}{*}{1990} & 0.18 & 0.07 & 0.48 & -0.38 & 0.08 & 0.05 & 0.13 & -0.11 \\
\hline & $70 \%$ & $41 \%$ & $275 \%$ & $-216 \%$ & $30 \%$ & $68 \%$ & $175 \%$ & $-143 \%$ \\
\hline \multirow{2}{*}{2000} & 0.17 & 0.08 & 0.48 & -0.39 & 0.03 & 0.05 & 0.07 & -0.09 \\
\hline & $83 \%$ & $45 \%$ & $291 \%$ & $-236 \%$ & $17 \%$ & $162 \%$ & $208 \%$ & $-270 \%$ \\
\hline \multirow{2}{*}{2005} & 0.17 & 0.07 & 0.42 & -0.32 & 0.03 & 0.05 & 0.05 & -0.07 \\
\hline & $84 \%$ & $43 \%$ & $247 \%$ & $-190 \%$ & $16 \%$ & $173 \%$ & $147 \%$ & $-220 \%$ \\
\hline \multirow{2}{*}{2010} & 0.16 & 0.08 & 0.34 & -0.25 & 0.04 & 0.06 & 0.05 & -0.07 \\
\hline & $81 \%$ & $48 \%$ & $207 \%$ & $-155 \%$ & $19 \%$ & $149 \%$ & $118 \%$ & $-167 \%$ \\
\hline
\end{tabular}

Table 5: Inequality between (Tb) and within (Tw) income-based country groupings and factorial decomposition of this inequality into material intensity $I(m)$ and affluence $I(y)$, 1960-2010. Source of data: Schaffartzik et al. (2014)

\section{Discussion: New material use patterns in the $21^{\text {st }}$ century}

The developments in global and national material use and affluence do not provide evidence for the successful international pursuit of efficient contraction and convergence. Rather than 
contracting, global material use increased sharply between 2000 and 2010 and per capita material consumption no longer converged. Material intensity was not improved enough to offset increasing affluence - the development was not efficient enough.

\subsection{On efficiency}

Efficiency gains (i.e., material intensity reductions) have contributed to decreasing metabolic rates and their impact as explanatory variables for material use has increased since 1960. At the global level, average material intensity improvements were too weak to counterbalance the growth and convergence in affluence that was simultaneously occurring (a number of studies have come to this conclusion, including: Giljum et al., 2014; Steger and Bleischwitz, 2009; UNEP, 2016). The period of accelerated growth in global material use between 2000 and 2010, however, saw material intensity increasing in many parts of the world (Table 2). These regions, which include China, South Korea, Qatar, Saudi Arabia, Brazil, and Chile, are global production hubs. The combined effect of rising material intensity and increasing production output (also noted by Pothen and Schymura, 2015) is rising global material resource consumption.

Increasingly unequal material intensity is also important in explaining inequality in metabolic rates, while affluence has lost significance. The negative correlation between affluence and material intensity (countries with higher income tend to be less material-intensive), as previously analysed by Steinberger et al. (2010), was weaker between 2000 and 2010 than in the previous decades.

The contribution of international inequality to global growth in material use has been conservatively estimated. A caveat of our data is that GDP is expressed in PPP currency units (see section 2). It is to be expected that, especially between 2000 and 2010, the strong GDP growth in emerging economies would be even more pronounced in terms of PPP than in real GDP (also see Steinberger et al., 2010). Accordingly, material intensity of these countries should be lower when calculated based on GDP in PPP currency units (as we have done) than it would be on the basis 
of real GDP. GDP in PPP units of currency most likely exhibits less inequality than real GDP (Steinberger et al., 2010).

\subsection{On contraction and convergence}

At the sub-global level, we found no evidence of individual countries able to sustain a path of dematerialization. Global growth in material use was not associated with stronger convergence of metabolic rates, although this is still commonly assumed to be occurring (e.g., Hirschnitz-Garbers et al., 2016). Instead, the distribution of metabolic rates became increasingly bipolar (at half and double the global average metabolic rate).

Based on the DMC indicator, we generate results on the material use within a country, no matter whether it is for domestic or foreign final demand (section 2). If production were to increasingly shift to low- or middle-income countries (as seems to be the case), it would simultaneously be shifting to places with higher material intensity, causing material use to increase globally (this is an argument made for energy intensity and increasing global energy use by Malm (2016)).

Research on the material footprint suggests that many countries with high levels of per capita material consumption (as reflected in the DMC) have even higher material footprints, i.e., indirectly appropriate material extracted in other economies (UNEP, 2016; Wiedmann et al., 2015). At the same time, countries with material consumption levels closer to the global average tend to supply exports for the high-consuming countries, i.e., use significant amounts of material domestically for the production of exports. The material footprint might therefore display greater inequality and different trends in the development of inequality than is the case for DMC. 


\subsection{From the first decade to the rest of the century}

The second half of the $20^{\text {th }}$ century was largely characterized by decreasing growth in metabolic rates in which increasing affluence and improving material intensity had balancing effects (Table 1). Global material use did not contract but was becoming more efficient and less unequal. The drastic change in this pattern in the $21^{\text {st }}$ century coincides with intensifying industrial production in the middle-income and emerging economies home to the majority of the global population (Giljum et al., 2014; Schaffartzik et al., 2014). If the economies currently industrializing are replicating the development trajectory of the early industrializers and not leap-frogging to high affluence and low material use, the environmental impacts will be disastrous.

\section{Conclusions}

In the international inequality in metabolic rates, material intensity - alongside affluence as the dominant factor - plays an increasingly important role. Material intensity improvements, however, have recently failed to counterbalance increasing affluence. In this development, countries and regions that are important global production centres and export-origins, in particular, have experienced rising material intensity as their affluence grew. Via trade, such material-intensive countries and the more material-efficient high-income countries are directly linked and their respective development trajectories cannot be viewed independently of one another. While the performance of early industrializers shows that efficient wealth is possible, the existing trade links lead us to question whether efficient wealth (and hence contraction and convergence) is globally possible or whether it is possible in some countries precisely because other countries specialize in material extraction, becoming neither as affluent nor as efficient. Affluence in high-income countries continues to grow while DMC is stabilized or even decreasing while in other countries affluence and DMC may grow at a similar pace, not allowing for significant efficiency gains. This pivotal issue necessitates research focussing specifically on the role of trade in metabolic 
inequality, including not only the trade flows themselves but also the material requirements directly and indirectly associated with extraction and production for export.

Trade links countries with vastly different material intensities during distinct phases of economic development. Increasing average consumption of materials appears to be almost unavoidable in the process of economic development and industrialization and, at the same time, threatens global sustainability. We found that during the period of time when global material use increased most drastically - in the first decade of the $21^{\text {st }}$ century - international inequality in material use increased. If increasing average consumption is not also the result of convergence in material use levels, then the 'justification' provided by economic development and industrialization must be questioned. What remains in this case is the inherent sustainability threat. If the high growth of material use and the associated environmental destruction and risk is not a clear enough warning sign for the potential consequences, then the new rise in material inequality should be. Globally speaking, use of material resources may be becoming less environmentally sustainable due to its sheer magnitude and less socially sustainable due to its inequality. 


\section{Acknowledgements}

The authors gratefully acknowledge funding by the Austrian Science Fund (FWF) within project P27590 and by the Spanish Ministerio de Economía y Competitividad project ECO2016-79072-

$P$.

\section{References}

Akenji, L., Bengtsson, M., 2014. Making Sustainable Consumption and Production the Core of Sustainable Development Goals. Sustainability 6, 513-529. doi:10.3390/su6020513

Akenji, L., Bengtsson, M., Bleischwitz, R., Tukker, A., Schandl, H., 2016. Ossified materialism: introduction to the special volume on absolute reductions in materials throughput and emissions. Journal of Cleaner Production. doi:10.1016/j.jclepro.2016.03.071

Alcott, B., 2005. Jevons' paradox. Ecological Economics 54, 9-21. doi:10.1016/j.ecolecon.2005.03.020

Angrick, M., Burger, A., Lehmann, H., 2013. Factor X: Policy, Strategies and Instruments for a Sustainable Resource Use. Springer Science \& Business Media.

Ashraf, M.A., Maah, M.J., Yusoff, I., Wajid, A., Mahmood, K., 2011. Sand mining effects, causes and concerns: A case study from Bestari Jaya, Selangor, Peninsular Malaysia. SRE 6, 1216-1231. doi:10.5897/SRE10.690

Binswanger, M., 2001. Technological progress and sustainable development: what about the rebound effect? Ecological Economics 36, 119-132. doi:10.1016/S0921-8009(00)00214-7

Cowell, F.A., 2011. Measuring Inequality, 3rd ed, LSE Perspectives in Economic Analysis. Oxford University Press, Oxford.

Druckman, A., Jackson, T., 2008. Measuring resource inequalities: The concepts and methodology for an area-based Gini coefficient. Ecological Economics 65, 242-252. doi:10.1016/j.ecolecon.2007.12.013

Duro, J.A., 2012. On the automatic application of inequality indexes in the analysis of the international distribution of environmental indicators. Ecological Economics 76, 1-7. doi:10.1016/j.ecolecon.2011.12.019

Duro, J.A., Padilla, E., 2006. International inequalities in per capita CO2 emissions: A decomposition methodology by Kaya factors. Energy Economics 28, 170-187. doi:10.1016/j.eneco.2005.12.004

Duro, J.A., Teixidó-Figueras, J., Padilla, E., 2016. Empirics of the International Inequality in CO2 Emissions Intensity: Explanatory Factors According to Complementary Decomposition Methodologies. Environ Resource Econ 63, 57-77. doi:10.1007/s10640-014-9840-6

Ehrlich, P.R., Holdren, J.P., 1971. Impact of Population Growth. Science, New Series 171, 1212-1217.

European Commission, 2011. A resource-efficient Europe-Flagship initiative under the Europe 2020 Strategy. COM (2011) 21.

Fischer-Kowalski, M., Krausmann, F., Giljum, S., Lutter, S., Mayer, A., Bringezu, S., Moriguchi, Y., Schütz, H., Schandl, H., Weisz, H., 2011. Methodology and Indicators of Economy-wide Material Flow Accounting. Journal of Industrial Ecology 15, 855-876. doi:10.1111/j.1530-9290.2011.00366.x

Foster, J.E., Wolfson, M.C., 2010. Polarization and the decline of the middle class: Canada and the U.S. J Econ Inequal 8, 247-273. doi:10.1007/s10888-009-9122-7 
Giljum, S., Dittrich, M., Lieber, M., Lutter, S., 2014. Global Patterns of Material Flows and their SocioEconomic and Environmental Implications: A MFA Study on All Countries World-Wide from 1980 to 2009. Resources 3, 319-339. doi:10.3390/resources3010319

Giljum, S., Eisenmenger, N., 2004. North-South Trade and the Distribution of Environmental Goods and Burdens: a Biophysical Perspective. The Journal of Environment Development 13, 73-100. doi:10.1177/1070496503260974

Hashimoto, S., Matsui, S., Matsuno, Y., Nansai, K., Murakami, S., Moriguchi, Y., 2008. What Factors Have Changed Japanese Resource Productivity? Journal of Industrial Ecology 12, 657-668. doi:10.1111/j.1530-9290.2008.00072.x

Hirschnitz-Garbers, M., Tan, A.R., Gradmann, A., Srebotnjak, T., 2016. Key drivers for unsustainable resource use - categories, effects and policy pointers. Journal of Cleaner Production, Absolute Reductions in Material Throughput, Energy Use and Emissions 132, 13-31. doi:10.1016/j.jclepro.2015.02.038

Hoekstra, R., van den Bergh, J.C.J.M., 2002. Structural Decomposition Analysis of Physical Flows in the Economy. Environmental and Resource Economics 23, 357-378. doi:10.1023/A:1021234216845

Jackson, T., 2016. Prosperity without Growth: Foundations for the Economy of Tomorrow, 2nd ed. Routledge.

Krausmann, F., Gingrich, S., Eisenmenger, N., Erb, K.-H., Haberl, H., Fischer-Kowalski, M., 2009. Growth in global materials use, GDP and population during the 20th century. Ecological Economics 68, 2696-2705. doi:10.1016/j.ecolecon.2009.05.007

Krausmann, F., Schandl, H., Eisenmenger, N., Giljum, S., Jackson, T., 2017a. Material Flow Accounting: Measuring Global Material Use for Sustainable Development. Annual Review of Environment and Resources 42, null. doi:10.1146/annurev-environ-102016-060726

Krausmann, F., Wiedenhofer, D., Lauk, C., Haas, W., Tanikawa, H., Fishman, T., Miatto, A., 2017b. Global socioeconomic material stocks rise 23-fold over the 20th century and require half of annual resource use. Proceedings of the National Academy of Sciences forthcoming.

Maddison, A., 2010. Historical Statistics for the World Economy: 1-2008 AD. Groningen Growth and Development Centre, Groningen.

Malm, A., 2016. Fossil capital: the rise of steam-power and the roots of global warming. Verso, London ; New York.

Meyer, A., 1999. The Kyoto Protocol and the Emergence of "Contraction and Convergence" as a Framework for an International Political Solution to Greenhouse Gas Emissions Abatement, in: Hohmeyer, O., Rennings, K. (Eds.), Man-Made Climate Change, ZEW Economic Studies. PhysicaVerlag HD, pp. 291-345. doi:10.1007/978-3-642-47035-6_15

Müller, D.B., Liu, G., Løvik, A.N., Modaresi, R., Pauliuk, S., Steinhoff, F.S., Bratteb $\varnothing$, H., 2013. Carbon Emissions of Infrastructure Development. Environ. Sci. Technol. 47, 11739-11746. doi:10.1021/es402618m

Pauliuk, S., Müller, D.B., 2014. The role of in-use stocks in the social metabolism and in climate change mitigation. Global Environmental Change 24, 132-142. doi:10.1016/j.gloenvcha.2013.11.006

Pichler, M., Schaffartzik, A., Haberl, H., Görg, C., 2017. Drivers of society-nature relations in the Anthropocene and their implications for sustainability transformations. Current Opinion in Environmental Sustainability 26-27, 32-36. doi:10.1016/j.cosust.2017.01.017

Pothen, F., Schymura, M., 2015. Bigger cakes with fewer ingredients? A comparison of material use of the world economy. Ecological Economics 109, 109-121. doi:10.1016/j.ecolecon.2014.10.009

Schaffartzik, A., Mayer, A., Gingrich, S., Eisenmenger, N., Loy, C., Krausmann, F., 2014. The global metabolic transition: Regional patterns and trends of global material flows, 1950-2010. Global Environmental Change 26, 87-97. doi:10.1016/j.gloenvcha.2014.03.013

Schaffartzik, A., Pichler, M., 2017. Extractive Economies in Material and Political Terms: Broadening the Analytical Scope. Sustainability 9, 1047. doi:10.3390/su9071047 
Schaffartzik, A., Wiedenhofer, D., Eisenmenger, N., 2015. Raw Material Equivalents: The Challenges of Accounting for Sustainability in a Globalized World. Sustainability 7, 5345-5370. doi:10.3390/su7055345

Schandl, H., Fischer-Kowalski, M., West, J., Giljum, S., Dittrich, M., Eisenmenger, N., Geschke, A., Lieber, M., Wieland, H., Schaffartzik, A., Krausmann, F., Gierlinger, S., Hosking, K., Lenzen, M., Tanikawa, H., Miatto, A., Fishman, T., 2017. Global Material Flows and Resource Productivity: Forty Years of Evidence. Journal of Industrial Ecology. doi:10.1111/jiec.12626

Schandl, H., West, J., 2010. Resource use and resource efficiency in the Asia-Pacific region. Global Environmental Change, 20th Anniversary Special Issue 20, 636-647. doi:10.1016/j.gloenvcha.2010.06.003

Shorrocks, A.F., 1984. Inequality Decomposition by Population Subgroups. Econometrica 52, 1369-1385. doi:10.2307/1913511

Shorrocks, A.F., 1982. Inequality decomposition by factor components. Econometrica 50, 193-211.

Steffen, W., Broadgate, W., Deutsch, L., Gaffney, O., Ludwig, C., 2015. The trajectory of the Anthropocene: The Great Acceleration. The Anthropocene Review 2053019614564785. doi:10.1177/2053019614564785

Steger, S., Bleischwitz, R., 2011. Drivers for the use of materials across countries. Journal of Cleaner Production, Critical Perspectives of Sustainable Development Research and Practice Utrecht 2009 19, 816-826. doi:10.1016/j.jclepro.2010.08.016

Steger, S., Bleischwitz, R., 2009. Decoupling GDP from resource use, resource productivity and competitiveness, in: Bleischwitz, R., Zhang, Z., Welfens, P. (Eds.), Sustainable Growth and Resource Productivity: Economic and Global Policy Issues. Greenleaf Publishing, Sheffield, pp. 172-193.

Steinberger, J.K., Krausmann, F., Eisenmenger, N., 2010. Global patterns of materials use: A socioeconomic and geophysical analysis. Ecological Economics 69, 1148-1158. doi:10.1016/j.ecolecon.2009.12.009

Teixidó-Figueras, J., Duro, J.A., 2015. The building blocks of International Ecological Footprint inequality: A Regression-Based Decomposition. Ecological Economics 118, 30-39. doi:10.1016/j.ecolecon.2015.07.014

Theil, H., 1967. Economics and information theory. North-Holland Pub. Co., Amsterdam.

UNEP, 2016. Global material flows and resource productivity. Authors: Heinz Schandl, Marina FischerKowalski, Jim West, Stefan Giljum, Monika Dittrich, Nina Eisenmenger, Arne Geschke, Mirko Lieber, Hanspeter Wieland, Anke Schaffartzik, Fridolin Krausmann, Sylvia Gierlinger, Karin Hosking, Manfred Lenzen, Hiroki Tanikawa, Alessio Miatto, Tomer Fishman (No. United Nations Environment Programme, International Resource Panel). Nairobi.

UNEP, 2011. Decoupling natural resource use and environmental impacts from economic growth, $A$ Report of the Working Group on Decoupling to the International Resource Panel. FischerKowalski, M., Swilling, M., von Weizsäcker, E.U., Ren, Y., Moriguchi, Y., Crane, W., Krausmann, F., Eisenmenger, N., Giljum, S., Hennicke, P., Romero Lankao, P., Siriban Manalang, A., Sewerin, S. United Nations Environment Programme, Nairobi.

United Nations, 2015. Transforming our world: the 2030 Agenda for Sustainable Development.

Victor, P., Hanna, S., Kubursi, A., 1998. How Strong is Weak Sustainability?, in: Faucheux, S., O'Connor, M., Straaten, J. van der (Eds.), Sustainable Development: Concepts, Rationalities and Strategies, Economy \& Environment. Springer Netherlands, pp. 195-210.

von Weizsäcker, E., Lovins, A.B., Lovins, L.H., 1997. Factor 4. Doubling Welfare, Halving Resource Use. A Report to the Club of Rome. Earthscan.

Wade, R.H., 2011. Globalization, growth, poverty, inequality, resentment and imperialism, in: Ravenhill, J. (Ed.), Global Political Economy. Oxford University Press, Oxford, pp. 373-409. 
West, J., Schandl, H., Heyenga, S., Chen, S., 2013. Resource Efficiency: Economics and Outlook for China. United Nations Environment Programme, Bangkok.

Wiedmann, T., Wilting, H.C., Lenzen, M., Lutter, S., Palm, V., 2011. Quo Vadis MRIO? Methodological, data and institutional requirements for multi-region input-output analysis. Ecological Economics, Special Section - Earth System Governance: Accountability and Legitimacy 70, 1937-1945. doi:10.1016/j.ecolecon.2011.06.014

Wiedmann, T.O., Schandl, H., Lenzen, M., Moran, D., Suh, S., West, J., Kanemoto, K., 2015. The material footprint of nations. PNAS 112, 6271-6276. doi:10.1073/pnas.1220362110

World Bank, 2016. World Bank GNI per capita Operational Guidelines \& Analytical Classifications. 